NASA/TM—2006-214660

\title{
Probabilistic Design of Composite Structures
}

\author{
Christos C. Chamis
}

Glenn Research Center, Cleveland, Ohio 


\section{NASA STI Program . . . in Profile}

Since its founding, NASA has been dedicated to the advancement of aeronautics and space science. The NASA Scientific and Technical Information (STI) program plays a key part in helping NASA maintain this important role.

The NASA STI Program operates under the auspices of the Agency Chief Information Officer. It collects, organizes, provides for archiving, and disseminates NASA's STI. The NASA STI program provides access to the NASA Aeronautics and Space Database and its public interface, the NASA Technical Reports Server, thus providing one of the largest collections of aeronautical and space science STI in the world. Results are published in both non-NASA channels and by NASA in the NASA STI Report Series, which includes the following report types:

- TECHNICAL PUBLICATION. Reports of completed research or a major significant phase of research that present the results of NASA programs and include extensive data or theoretical analysis. Includes compilations of significant scientific and technical data and information deemed to be of continuing reference value. NASA counterpart of peer-reviewed formal professional papers but has less stringent limitations on manuscript length and extent of graphic presentations.

- TECHNICAL MEMORANDUM. Scientific and technical findings that are preliminary or of specialized interest, e.g., quick release reports, working papers, and bibliographies that contain minimal annotation. Does not contain extensive analysis.

- CONTRACTOR REPORT. Scientific and technical findings by NASA-sponsored contractors and grantees.
- CONFERENCE PUBLICATION. Collected papers from scientific and technical conferences, symposia, seminars, or other meetings sponsored or cosponsored by NASA.

- SPECIAL PUBLICATION. Scientific, technical, or historical information from NASA programs, projects, and missions, often concerned with subjects having substantial public interest.

- TECHNICAL TRANSLATION. Englishlanguage translations of foreign scientific and technical material pertinent to NASA's mission.

Specialized services also include creating custom thesauri, building customized databases, organizing and publishing research results.

For more information about the NASA STI program, see the following:

- Access the NASA STI program home page at http://www.sti.nasa.gov

- E-mail your question via the Internet to help@sti.nasa.gov

- Fax your question to the NASA STI Help Desk at 301-621-0134

- Telephone the NASA STI Help Desk at 301-621-0390

- Write to:

NASA STI Help Desk

NASA Center for AeroSpace Information 7115 Standard Drive Hanover, MD 21076-1320 
NASA/TM-2006-214660

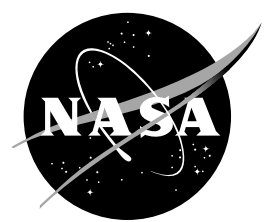

\section{Probabilistic Design of Composite Structures}

Christos C. Chamis

Glenn Research Center, Cleveland, Ohio

Prepared for the

International Conference on Computational and Experimental Engineering and Sciences sponsored by the ICCES'07 Organizing Committees

Miami Beach, Florida, January 3-8, 2007

National Aeronautics and

Space Administration

Glenn Research Center

Cleveland, Ohio 44135 
This report is a preprint of a paper intended for presentation at a conference.

Because changes may be made before formal publication, this preprint is made available with the understanding that it will not be cited or reproduced without the permission of the author.

Level of Review: This material has been technically reviewed by technical management.

Available from

NASA Center for Aerospace Information 7115 Standard Drive

Hanover, MD 21076-1320
National Technical Information Service 5285 Port Royal Road Springfield, VA 22161 


\title{
Probabilistic Design of Composite Structures
}

\author{
Christos C. Chamis \\ National Aeronautics and Space Administration \\ Glenn Research Center \\ Cleveland, Ohio 44135
}

\section{Summary}

A formal procedure for the probabilistic design evaluation of a composite structure is described. The uncertainties in all aspects of a composite structure (constituent material properties, fabrication variables, structural geometry, and service environments, etc.), which result in the uncertain behavior in the composite structural responses, are included in the evaluation. The probabilistic evaluation consists of: (1) design criteria, (2) modeling of composite structures and uncertainties, (3) simulation methods, and (4) the decision-making process. A sample case is presented to illustrate the formal procedure and to demonstrate that composite structural designs can be probabilistically evaluated with accuracy and efficiency.

\section{Introduction}

Composite materials are widely used in modern structures for high performance and reliability. However, because these structures usually operate in hostile and random service environments, it is difficult to predict the structural performance. In addition, experiments show that the composite structural behavior exhibits wide scatter as a result of the inherent uncertainties in design variables. The design variables, known as primitive variables, include the fiber and matrix material properties at the constituent level; fiber and void volume ratios, ply misalignment and ply thickness' the fabrication process, and random structure size, boundary conditions, loadings, and environment.

The scatter in the structural behavior cannot be computationally simulated by the traditional deterministic methods that use a safety factor to account for uncertain structural behavior; thus, the structural reliability cannot be discerned. A probabilistic design methodology is needed to accurately determine the structural reliability of a composite structure.

NASA Glenn Research Center has developed a formal methodology to efficiently and accurately quantify the scatter in the composite structural response and to evaluate the composite structural design, while accounting for the uncertainties at all composite levels (constituent, ply, laminate, and structure) (fig. 1). This methodology, which integrates micro- and macrocomposite mechanics and laminate theories, finite element methods, and probability algorithms, was implemented through the computer code IPACS (Integrated Probabilistic Assessment of Composite Structures) (fig. 2) (ref. 1). IPACS is used to evaluate composite structures probabilistically for all types of structural performances such as instability, clearance, damage initiation, delamination, microbuckling, fiber crushing, and resonance damage. Since IPACS uses a special probability algorithm FPI (Fast Probability Integrator) (ref. 2) instead of the conventional Monte Carlo simulation, tremendous computational time can be saved. Therefore, a probabilistic composite structural analysis, which cannot be done traditionally, becomes desirable especially for large structures with many uncertain variables. A typical case is analyzed herein to demonstrate the code IPACS for the probabilistic evaluation of composite structures and to illustrate the formal design evaluation methodology. 


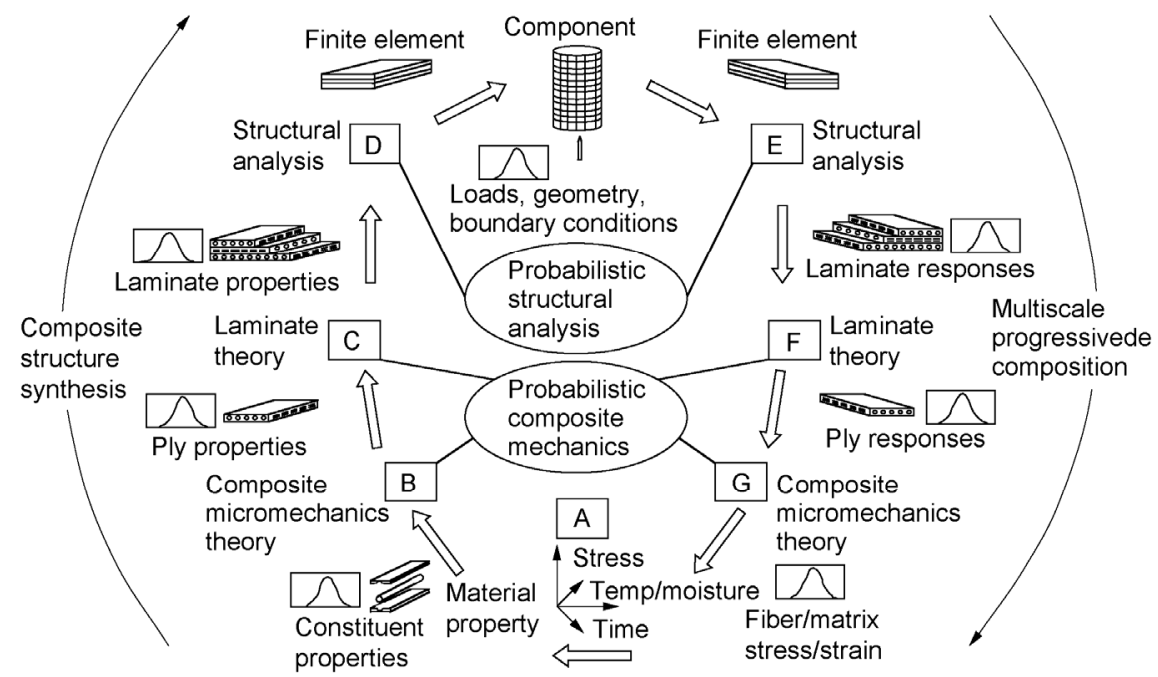

Figure 1.-Concept of probabilistic assessment of composite structures.

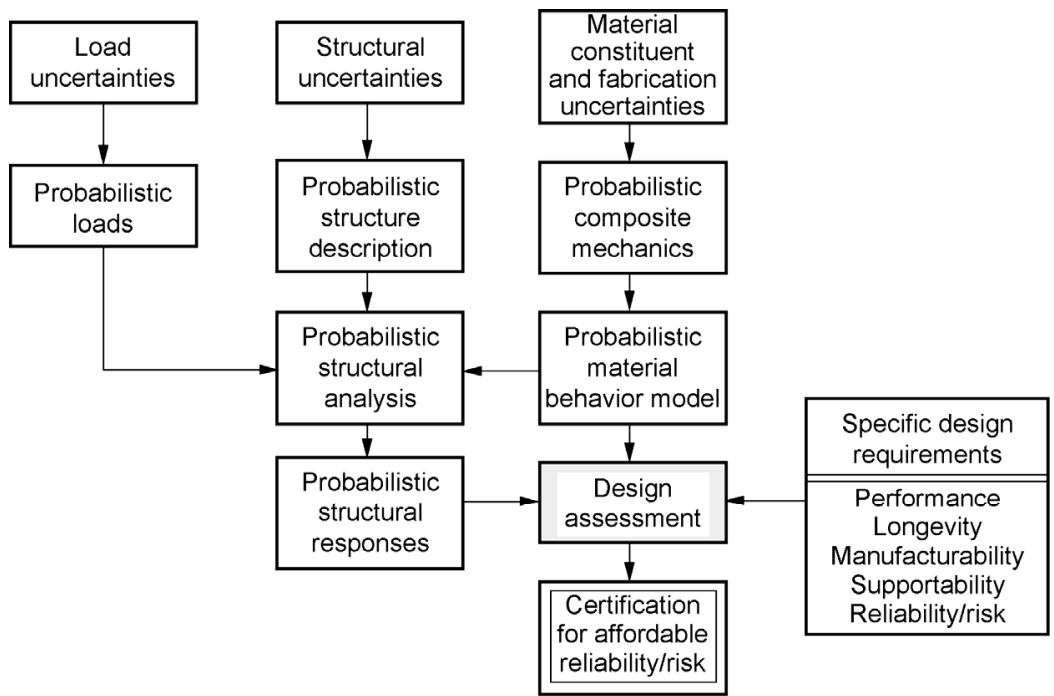

Figure 2.-Probabilistic design assessment of composite structures.

\section{Fundamental Approach}

The fundamental approach for the probabilistic evaluation is as follows:

(1) Identify all possible uncertain variables at all composite scale levels.

(2) Determine the probabilistic distribution function (PDF) for each variable.

(3) Process all random variables through an analyzer that consists of micro and macrocomposite mechanics, laminate theories, structural mechanics, and probability theories.

(4) Extract useful information from the output of the analyzer and check against the probabilistic design criteria.

The uncertainties in a composite structural design can originate at different composite scale levels. At the constituent level, the material properties for the fiber and matrix are the major sources of uncertainties. Typical values are listed in table I. At all stages of the fabrication process the fabrication variables, such as fiber volume ratio, void volume ratio, ply misalignment and ply thickness, show considerable scatter. At the structure level, variation of the geometry during the assembly stage, uncertain 
boundary conditions, and random thermal-mechanical loads contribute significantly to the scatter in the composite structural response.

TABLE I.-MATERIAL PROPERTIES AT THE CONSTITUENT LEVEL FOR SKIN AND STRINGERS

\begin{tabular}{|c|c|c|c|}
\hline Property & Assumed distribution type & Mean $^{\mathrm{a}}$ & Assumed uncertainty scatter \\
\hline $\mathrm{E}_{\mathrm{f} 11}, \mathrm{Mpsi}$ & Normal & 31.0 & $\pm 5 \%$ from mean \\
\hline $\mathrm{E}_{\mathrm{f} 22}, \mathrm{Mpsi}$ & & 2.0 & $\pm 5 \%$ from mean \\
\hline $\mathrm{G}_{\mathrm{f} 12}, \mathrm{Mpsi}$ & & 2.0 & $\pm 5 \%$ from mean \\
\hline $\mathrm{G}_{\mathrm{f} 23}, \mathrm{Mpsi}$ & & 1.0 & $\pm 5 \%$ from mean \\
\hline $\mathrm{V}_{\mathrm{f} 12}$ & & 0.2 & $\pm 5 \%$ from mean \\
\hline $\mathrm{V}_{\mathrm{f} 23}$ & & 0.25 & $\pm 5 \%$ from mean \\
\hline$\alpha_{\mathrm{f} 11}, \mathrm{ppm} /{ }^{\circ} \mathrm{F}$ & & -0.55 & $\pm 5 \%$ from mean \\
\hline$\alpha_{\mathrm{f} 22}, \mathrm{ppm} /{ }^{\circ} \mathrm{F}$ & & $\begin{array}{r}5.6 \\
0.92\end{array}$ & $\pm 5 \%$ from mean \\
\hline$\rho_{f}$, lb/in..$^{3}$ & Constant & $\begin{array}{r}0.063 \\
10000\end{array}$ & $\pm 5 \%$ from mean \\
\hline $\mathrm{N}_{\mathrm{f}}$ & Normal & 0.0003 & $\pm 5 \%$ from mean \\
\hline $\mathrm{d}_{\mathrm{f}}$, in. & & 0.17 & $\pm 5 \%$ from mean \\
\hline & & 580 & $\pm 5 \%$ from mean \\
\hline $\mathrm{K}_{\mathrm{f} 11}, \mathrm{Btu} \cdot \mathrm{in} . / \mathrm{hr}$ in. ${ }^{2}$ & & 58 & $\pm 5 \%$ from mean \\
\hline $\mathrm{K}_{\mathrm{f} 2}$, Btu. in./hr in. ${ }^{2}$ & U & 58 & $\pm 5 \%$ from mean \\
\hline & $\begin{array}{l}\text { Weibull } \\
\text { Weibull }\end{array}$ & $\begin{array}{l}400 \\
400\end{array}$ & $\begin{array}{l} \pm 5 \% \text { from mean } \\
+5 \% \text { from mean }\end{array}$ \\
\hline $\mathrm{K}_{\mathrm{f} 33}$, Btu. in. $/ \mathrm{hr}$ in. ${ }^{2}$ & Normal & 0.5 & $\pm 5 \%$ from mean \\
\hline & & 0.185 & $\pm 5 \%$ from mean \\
\hline $\mathrm{S}_{\mathrm{fT}}, \mathrm{ksi}$ & & 0.35 & $\pm 5 \%$ from mean \\
\hline $\mathrm{S}_{\mathrm{fC}}, \mathrm{ksi}$ & & 42.8 & $\pm 5 \%$ from mean \\
\hline $\mathrm{E}_{\mathrm{m}}, \mathrm{Mpsi}$ & & 0.0443 & $+5 \%$ from mean \\
\hline $\mathrm{G}_{\mathrm{m}}, \mathrm{Mpsi}$ & & 0.25 & $\pm 5 \%$ from mean \\
\hline $\mathrm{V}_{\mathrm{m}}$ & & 1.25 & $\pm 5 \%$ from mean \\
\hline$\alpha_{\mathrm{m}}, \mathrm{ppm} /{ }^{\circ} \mathrm{F}$ & Weibull & 15 & $\pm 5 \%$ from mean \\
\hline$\rho_{\mathrm{m}}, \mathrm{lb} / \mathrm{in} .^{3}$ & Weibull & $\begin{array}{l}35 \\
13\end{array}$ & $\pm 5 \%$ from mean \\
\hline $\mathrm{C}_{\mathrm{m}}, \mathrm{Btu} / \mathrm{in} .{ }^{\circ} \mathrm{F}$ & $\begin{array}{l}\text { Weibull } \\
\text { Normal }\end{array}$ & $\begin{array}{r}13 \\
0.004\end{array}$ & $\pm 5 \%$ from mean \\
\hline $\begin{array}{l}\mathrm{K}_{\mathrm{m}}, \mathrm{Btu} \cdot \mathrm{in} . / \mathrm{hr} \text { in. } \\
{ }^{\circ} \mathrm{F}\end{array}$ & Normal & 0.002 & $\pm 5 \%$ from mean \\
\hline $\mathrm{S}_{\mathrm{mT}}, \mathrm{ksi}$ & & & I5\% lrom mean \\
\hline $\mathrm{S}_{\mathrm{mC}}, \mathrm{ksi}$ & & & $+5 \%$ from mean \\
\hline $\mathrm{S}_{\mathrm{mS}}, \mathrm{ksi}$ & & & $\pm 5 \%$ from mean \\
\hline $\begin{array}{l}\beta_{\mathrm{m}},(\text { in./in. }) / 1 \% \\
\text { moist }\end{array}$ & & & $\pm 5 \%$ from mean \\
\hline $\mathrm{D}_{\mathrm{m}}$, in. $^{3} / \mathrm{sec}$ & & & $\pm 5 \%$ from mean \\
\hline & & & $\pm 5 \%$ from mean \\
\hline
\end{tabular}

${ }^{\mathrm{a}}$ Typical values for graphite-fiber/epoxy-matrix composites at 0.6 fiber volume ratio.

\section{Probabilistic Composite Structural Design Evaluation}

This paper describes a probabilistic design evaluation methodology for composite structures with an acceptable or preassigned reliability. The details of the evaluation are described in the following three steps.

Step 1: Probabilistic Design Criteria Setup: A typical design criterion can be stated as follows: The probability of a failure event should be less than an acceptable value, say $10^{-3}$. A failure event occurs when a structural response is greater than the allowable response. This probability is defined as the failure probability. The allowable response divides the possible response domain into safe and failure regions as shown in figure 3 . The predicted failure probability is the area under the probability density function in the failure region. The critical response (fig. 3) is determined by IPACS such that the probability of a response exceeding this critical value is in the safe region. When the critical response falls within the safe region, the design is acceptable. When the critical response falls within the failure region, the design is 


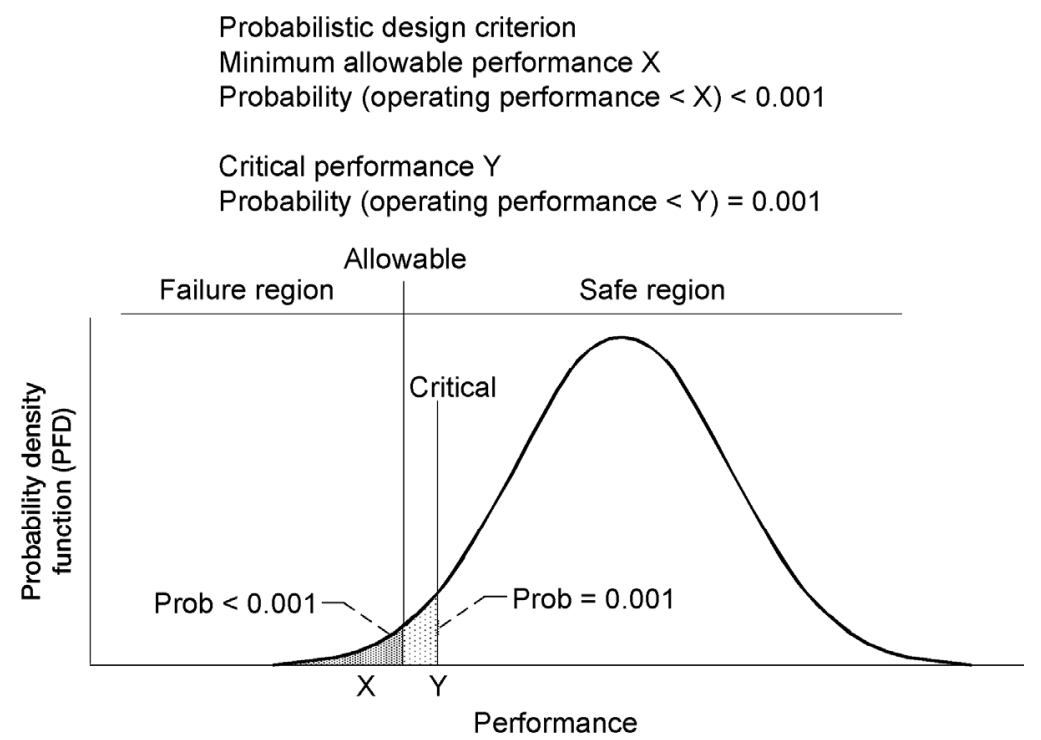

Figure 3.-Safe and failure regions in a probability space.

unacceptable and requires a redesign. Sample probabilistic design criteria for the various failure modes are described as follows: (1) Instability - The probability that the buckling load is smaller than the design load should be less than $10^{-3}$. (2) Clearance-The probability that the nodal displacement is greater than the allowable tolerance should be less than $10^{-3}$. (3) Resonance avoidance-The probability that the natural frequency is greater that its upper bound should be less than $10^{-3}$. (4) Delamination-The probability of delamination occurrence should be less than $10^{-3}$.

Step 2: Probabilistic Simulation Using IPACS: IPACS integrates several NASA in-house computer codes developed in recent years such as COBSTRAN (Composite Blade Structural Analyzer), PICAN (Probabilistic Integrated Composite Analyzer) and MHOST (Marc Hot Section Technology).

COBSTRAN is a dedicated finite element model generator for structural analysis of composite structures. PICAN uses ICAN (Integrated Composite Analyzer) computer code for composite mechanics. This code has evolved over the last 40 years and has been verified with experimental data for all aspects of composites. PICAN enables the computation of the perturbed and probabilistic composite material properties at the ply and laminate levels. MHOST performs structural analyses using verified finite element methods. These analyses determine the perturbed and probabilistic structural response at global, laminate, and ply levels. PICAN and MHOST share the FPI module for the application of the fast probability integration algorithm to obtain cumulative distribution functions (CDF's) of the material properties and the structural responses.

FPI is an approximate technique for the probabilistic analysis of the structural performance and has the major advantage of speed. FPI techniques are orders of magnitude more efficient than Monte Carlo simulation methods. This is especially true in the tails regions of the distribution; that is, at very high or low probabilities since the FPI solution time is independent of the probability level. Conversely, in Monte Carlo simulation methods, the computational time increases with very high or low probability levels.

Also, FPI allows evaluation of information that describes the relative importance of each random variable. These sensitivity factors can be a valuable aid in optimizing a design.

In IPACS, the probabilistic evaluation of composite structures starts with the identification of uncertain primitive variables at constituent and ply levels. These variables are then selectively perturbed several times to create a data base. The data base is used to establish the relationship between the desired structural response (or the desired material property) and the primitive variables. For every given perturbed variable, micromechanics is applied to determine the corresponding perturbed mechanical properties at the ply and laminate levels. Laminate theory is then used to ascertain the resultant forcemoment strain-curvature relationship. With this relationship at the laminate level, a finite element 
perturbation analysis is performed to find the structural response that corresponds to the selectively perturbed primitive variables. This process is repeated until enough data are generated and the proper relationship between structural response and primitive variables can be established through a numerical procedure.

Step 3: Decision Making and Redesign: IPACS simulates the PDF of a given structural response, such as buckling load, displacement, local stress, local strength, vibration frequencies, and fatigue life. The probability of a design violation for each criterion can be calculated with these PDF functions. When the failure probability is greater than the acceptable value, say $10^{-3}$, the composite structural design should be rejected. To redesign a composite structure, one can use the sensitivity factors from the IPACS analysis. Sensitivity factors rank the random variables based on their contribution to this failure probability. Therefore, a redesign will be guided by this information with manufacturing control of the mean and the standard deviation (stdv) of the appropriate random variables.

\section{Demonstration Case and Discussion}

A stiffened composite cylindrical pipe is probabilistically designed against probabilistic design criteria. The cylindrical pipe is $2 \mathrm{ft}$. in diameter and $20 \mathrm{ft}$. long. The structure is modeled by 588 fournoded shell elements and 600 active nodes ( 6 degrees of freedom per node). The composite pipe consists of the skin, three horizontal circumferential frames, and four vertical stringers. The laminate configurations for the skin, frames, and stringers are $\left[+45 / 0_{2} / \pm 45 / 0_{2} / \pm 45 / 0 / 90\right]_{\mathrm{s}},\left[0_{24}\right]$ and $\left[0_{24}\right]$, respectively. The pipe is assumed to be supported at one end by a set of translational and torsional spring constants and free at the other end. When the spring constant approaches infinity, a completely fixed boundary condition is simulated. When the spring constants are set to zero, a free boundary condition is simulated. For a given set of spring constants, a partially fixed boundary condition is modeled. The pipe is subjected to axial $\left(\mathrm{F}_{\mathrm{x}}\right)$ and lateral $\left(\mathrm{F}_{\mathrm{y}}\right)$ loads as well as torsional moments $\left(\mathrm{M}_{\mathrm{xx}}\right)$ at its free end.

The uncertain variables are identified at the constituent, ply, and structure levels. At the constituent level, 17 material properties for the graphite fiber and 12 for the epoxy matrix of the skin, frames, and stringers are assumed to be uncertain variables. Their probability distribution types and associated parameters are listed in table I. At the ply level, the fabrication variables (fiber and void volume ratio, ply orientation, and ply thickness) are treated as random variables. Their statistics are shown in table II. At the structure level, spring constants that simulate a partially fixed boundary condition are assigned by a probability distribution as are the loading conditions. Their statistics are shown in table III. The composite pipe was designed against two design criteria: clearance and delamination. The results showed that the uncertainty range in the end displacement is between 1 and 3 percent. of the pipe length and it is most sensitive to uncertainties in the wall thickness perimeter variables. The probable delamination failure is most sensitive to sheer strength of the wall thinness.

TABLE II.-FABRICATION VARIABLES AT PLY LEVEL

\begin{tabular}{|l|c|c|c|}
\hline \multicolumn{1}{|c|}{ Variable } & Assumed distribution type & Mean & Assumed uncertainty scatter \\
\hline Fvr & Normal & 0.60 & 0.05 \\
vvr & & 0.02 & 0.05 \\
$\theta_{\mathrm{p}}$, deg & & 0.00 & $0.9($ stvd $)$ \\
$\mathrm{t}_{\mathrm{psk}}$, in. & & 0.005 & 0.05 \\
$\mathrm{t}_{\mathrm{pst}}$, in. & & 0.02 & 0.05 \\
\hline
\end{tabular}

TABLE III.-UNCERTAINTIES IN STRUCTURAL LEVEL

\begin{tabular}{|l|c|c|c|}
\hline \multicolumn{1}{|c|}{ Uncertainty } & Assumed distribution type & Mean & Assumed uncertainty scatter \\
\hline $\mathrm{K}_{\mathrm{cTR}}, \mathrm{lb} /$ in. & Normal & $30 \times 10^{6}$ & 0.20 \\
$\mathrm{~K}_{\mathrm{cTO}}, \mathrm{lb}$-in./rad & & $12 \times 10^{2}$ & 0.20 \\
$\mathrm{~F}_{\mathrm{x}}$, kip & & 288 & 0.05 \\
$\mathrm{~F}_{\mathrm{y}}$, kip & & 5.76 & 0.05 \\
$\mathrm{M}_{\mathrm{xx}}$, kip-ft & & 576 & 0.05 \\
\hline
\end{tabular}




\section{Concluding Remarks}

A formal methodology is described in this report for the probabilistic design evaluation of composite structures. This methodology, integrating micro and macrocomposite theory, structural mechanics (finite element methods), and probability algorithms, performs a probabilistic evaluation of composite structural designs considering all identifiable uncertain variables at all composite levels. Composite structural designs can be evaluated against specific probabilistic design criteria demonstrating that such designs can be computationally evaluated by using the probabilistic computer code IPACS. Information for an efficient design can also be obtained. Specifically, for the demonstration case, the uncertainty range in the end displacement was between 1 and 3 percent of the pipe length and was most sensitive to the uncertainties in the skin-related primitive variables. Conversely, probable delamination failure was most sensitive to the shear strength of the skin.

\section{References}

1. Chamis, C.C., and Shiao, M.C.: IPACS - Integrated Probabilistic Assessment of Composite Structures: Code Development and Applications. Third NASA Advanced Composite Technology Conference, vol. 1, Pt. 2, J.G. Davis, Jr. and H.L. Bohon, eds., NASA CP-3178-Vol-1-PT-2, 1993, pp. 987-999.

2. Wu, Y.T.: Demonstration of a New, Fast Probability Integration Method for Reliability Analysis. Advances in Aerospace Structural Analysis, O.H. Burnside and C.H. Parr, eds., ASME, New York, 1985, pp. 63-73. 


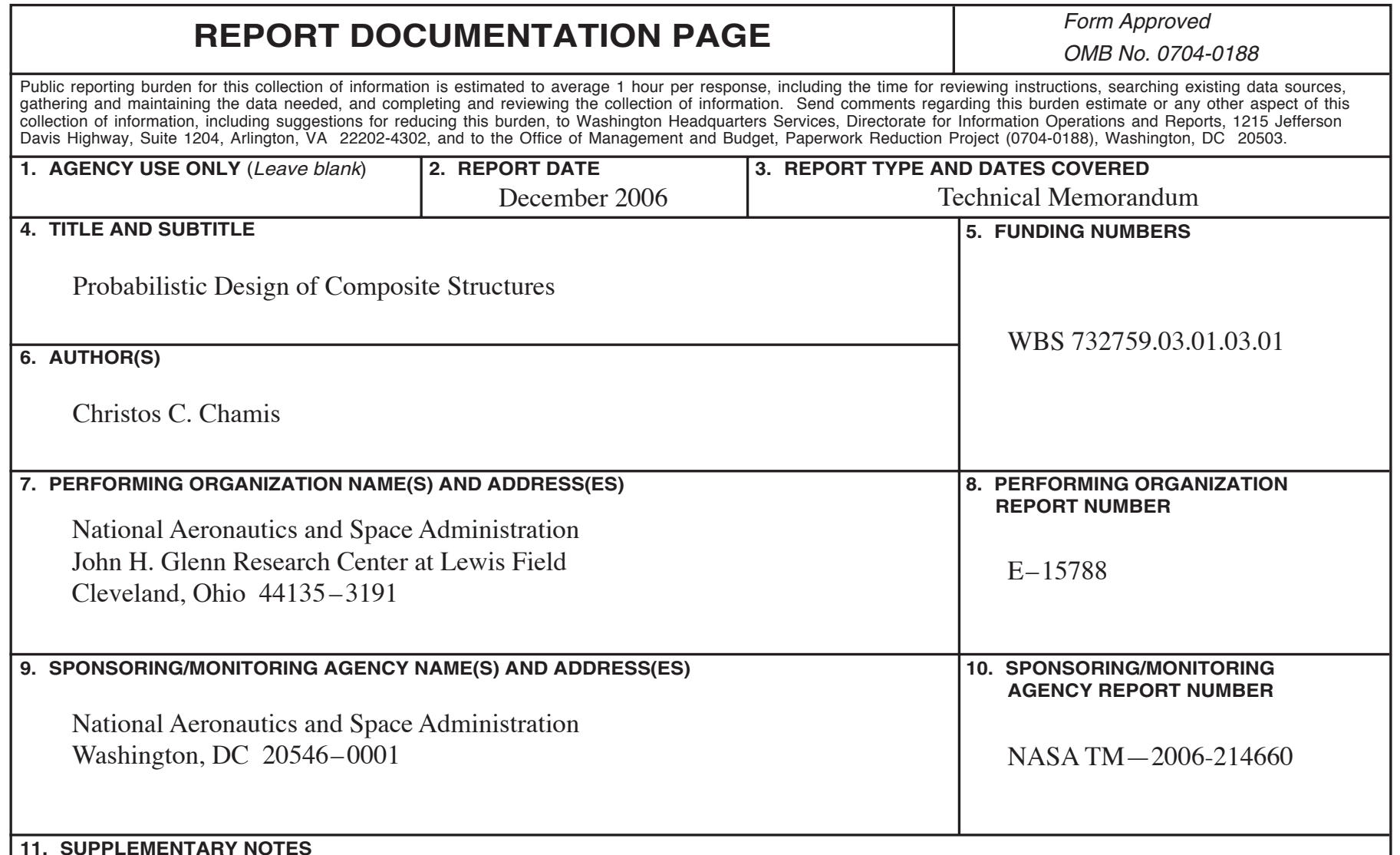

Prepared for the International Conference on Computational and Experimental Engineering and Sciences sponsored by the IECCES '07 Organizing Committees, Miami Beach, Florida, January 3-8, 2007. Responsible person

Christos C. Chamis, organization code R, 216-433-3252.

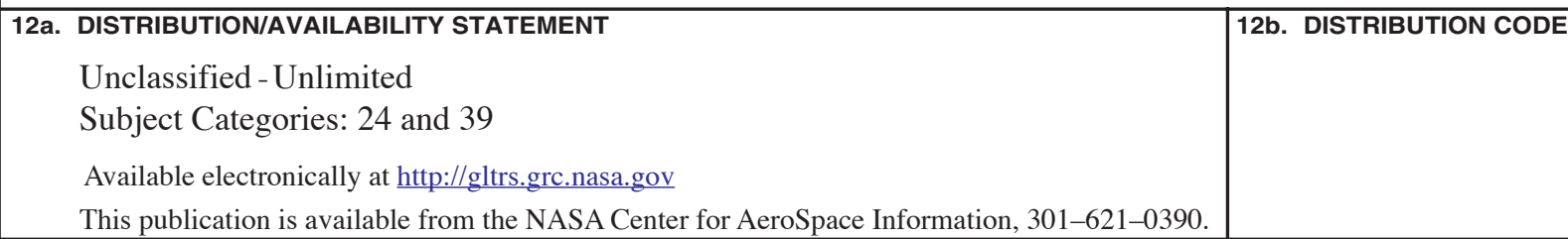

\section{ABSTRACT (Maximum 200 words)}

A formal procedure for the probabilistic design evaluation of a composite structure is described. The uncertainties in all aspects of a composite structure (constituent material properties, fabrication variables, structural geometry, and service environments, etc.), which result in the uncertain behavior in the composite structural responses, are included in the evaluation. The probabilistic evaluation consists of: (1) design criteria, (2) modeling of composite structures and uncertainties, (3) simulation methods, and (4) the decision-making process. A sample case is presented to illustrate the formal procedure and to demonstrate that composite structural designs can be probabilistically evaluated with accuracy and efficiency.

\begin{tabular}{|c|c|c|c|}
\hline \multirow{3}{*}{\multicolumn{3}{|c|}{$\begin{array}{l}\text { 14. SUBJECT TERMS } \\
\text { Structural mechanies; Aeronautics; Quality assurance and reliability; } \\
\text { Computer programming }\end{array}$}} & \multirow{4}{*}{$\begin{array}{l}\text { 15. NUMBER OF PAGES } \\
12 \\
\text { 16. PRICE CODE } \\
\text { 20. LIMITATION OF ABSTRACT }\end{array}$} \\
\hline & & & \\
\hline & & & \\
\hline $\begin{array}{l}\text { 17. SECURITY CLASSIFICATION } \\
\text { OF REPORT }\end{array}$ & $\begin{array}{l}\text { 18. SECURITY CLASSIFICATION } \\
\text { OF THIS PAGE }\end{array}$ & $\begin{array}{l}\text { 19. SECURITY CLASSIFICATION } \\
\text { OF ABSTRACT }\end{array}$ & \\
\hline Unclassified & Unclassified & Unclassified & \\
\hline NSN 7540-01-280-5500 & & & $\begin{array}{l}\text { ndard Form } 298 \text { (Rev. 2-89) } \\
\text { scribed by ANSI Std. Z39-18 } \\
-102\end{array}$ \\
\hline
\end{tabular}



